2018 Global Marketing Conference at Tokyo Proceedings: 1098-1106 (July 2018) https://doi.org/10.15444/GMC2018.09.05.01

\title{
THE PERCEPTION OF ACTIVE LISTENING PRACTICE ON SOCIAL NETWORKS
}

\author{
Lídia Silveira Pina, Instituto Universitário de Lisboa (ISCTE-IUL), Lisbon, Portugal ${ }^{1)}$ \\ Sandra Maria Correia Loureiro, Instituto Universitário de Lisboa (ISCTE-IUL) and \\ Business research Unit (BRU/UNIDE) and SOCIUS, Lisbon, Portugal ${ }^{2)}$ \\ Paulo Rita, Instituto Universitário de Lisboa (ISCTE-IUL), BRU-IUL \\ and NOVA Information Management School (NOVA IMS), Universidade Nova \\ deLisboa, Lisbon, Portugal ${ }^{2)}$
}

Eduardo Moraes Sarmento, University Lusófona and ISEG-Universit of Lisbon, Lisbon, Portugal ${ }^{4)}$

Ricardo G. Bilro, Instituto Universitário de Lisboa (ISCTE-IUL) and Business research

Unit (BRU/UNIDE), Lisbon and IPAM-Universidade Europeia, Portugal ${ }^{3)}$

João Guerreiro, Instituto Universitário de Lisboa (ISCTE-IUL) and Business research Unit (BRU/UNIDE), Lisbon, Portugal ${ }^{6)}$

\begin{abstract}
The evolution of the internet led to a shift in the business operations environment, giving rise to a plethora of challenges and opportunities for companies. Social networks have become attractive to companies due to their interactive nature, not only facilitating conversations with consumers, but also increasing the possibility of enhancing the online consumer brand engagement. Additionally, social networks and online brand communities increased consumers' possibility of developing an active role in companies' decision-making process, through the creation of user generated content, together with the opinion sharing and directly information exchange with brands and other internet users. The main objective of this research is to ascertain whether the active listening practice can contribute, in some way, to the improvement of the relationship maintained between consumers and brands. The current study suggests the adaptation of the active listening practice on the online field, as an attempt to enhance the communication strategies held by brands. Hence, this research seeks to demonstrate that this practice can improve the consumer-brand relationship through the development of two qualitative studies, as main approach, where the findings extracted in the first study will be used as inputs to the second one.
\end{abstract}

Keywords: consumer-brand relationship, social networks, online consumer brand engagement, active listening

\section{INTRODUCTION}

Social media has been responsible for changing the elementary rules of communication, especially between companies and their audiences (Maggiani, 2012). Social networking

\footnotetext{
1 lidia_pina@iscte-iul.pt

2 sandramloureiro@netcabo.pt

3 paulo.rita@iscte-iul.pt

4 emoraessarmento@gmail.com

5 bilro.ricardo@gmail.com

6 joao.guerreiro@iscte-iul.pt
} 


\section{Global Marketing Conference at Tokyo Proceedings}

sites decreased marketers' power of promoting products and increased the power held by consumers. Thus, organizations have started to recognize social networks as powerful channels in which they can establish relationships with their consumers and listen to what they have to say. Hence, organizations are being "forced" to improve their online presence since a close active relationship with their consumers can lead to involvement, engagement and meaningful contributions, which might lead to the increase of brand value.

Meanwhile, consumers are becoming more demanding when choosing a brand with whom to establish relationships with. Consumers do not want brands saying their target is important, if those same brands do not demonstrate to care about their consumers in the end. Instead, consumers want brands which let them contribute and assist in their decision-making process, that is, brands have to start using active listening as a way of obtaining consumer insights to be used as inputs in their communication and marketing strategies.

The main objective of this paper is to ascertain whether the active listening practice can contribute, in some way, to the improvement of the relationship maintained between consumers and brands, or not. In that sense, the practice of active listening, directly linked with online engagement, might present a new solution or alternative to the actual market saturation, in terms of business opportunities. So, the specific research question is: Can the practice of active listening improve the relationship between consumers and brands?

The paper is organized in several sections. The first one is entirely dedicated to literature review, where each relevant concept embedded in the paper is discussed in detail. The second section presents the methodology considered most appropriate for the problem in analysis. The third section includes an extensive and meticulous analysis to the findings extracted from both studies performed during the methodological process (Study 1 and Study 2). Finally, the last section displays the conclusions extracted throughout the paper as well as some specific managerial implications.

\section{THEORETICAL OVERVIEW}

Consumer-brand relationship (CBR) started to attract interest and acquire relevance in the late nineties of 20th century. Since then, several types of organizations started to become increasingly interested in acquiring knowledge about the way consumers connect with brands, to understand the reason why some brands are preferred and loved over others. As a result, organizations started to adopt consumer-centric strategies as a way of obtaining this type of expertise in an effective way (Loureiro, 2012) and as a key goal of many marketing professionals in having an engaged consumer base (Dessart et al., 2015). Part of the engagement importance can be explained by the fact that companies nowadays live in a highly competitive world, which make them search for new business opportunities to transform into competitive advantages in order to be successful in the market.

Social media is another paradigm which needs to be considered in this equation.Thanks to this phenomenon, the communication model became multidimensional, allowing interactions in several ways, including consumer-to-business.

Atending previous considerations, this paper is mainly focused on several concepts, as illustrated in Figure 1, specifically active listening (AL), social networks, and consumer-brand relationship in determining the choice of online brand communities, online engagement and user generated content. 


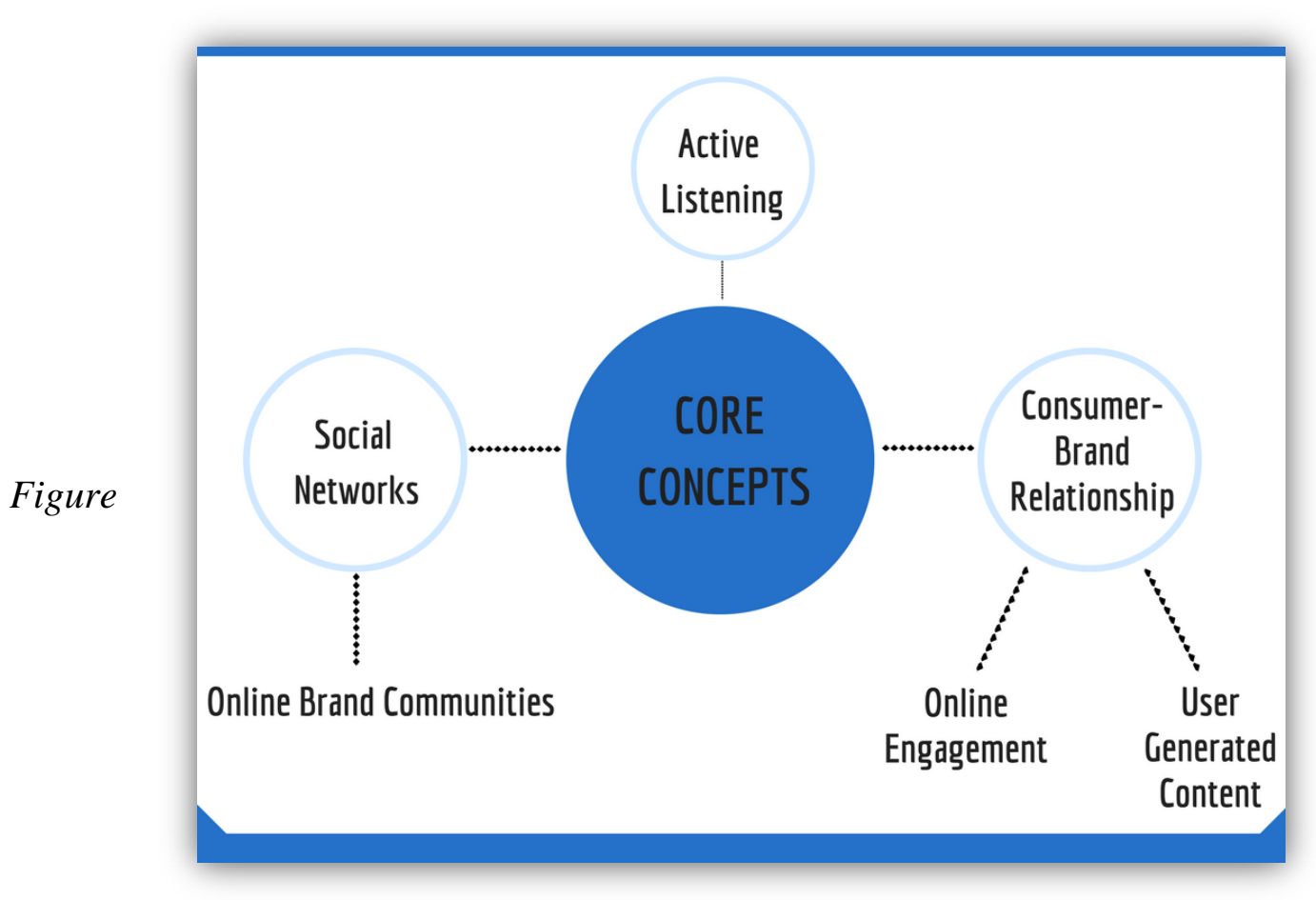

$1:$

Main concepts used in this study.

Each of the three main concepts presented above has different origins and features, which implies the study of three distinct marketing fields: relationship marketing, marketing communications and consumer behavior, thereby requiring a logical and simple organization of the work. This organization implies the allocation of the information exposed, throughout the entire work, to a specific section avoiding misunderstandings and providing the reader a broader understanding of the subjects addressed.

The literature review reveals that the AL concept is present in several fields such as psychology, nursing, advocacy and communication, among others, and has helped those fields to overcome several difficulties. In nursing, active listening is used to improve the efficiency of patient diagnosis (Heslip, 2015), while in communication is used as a way of improving the number of agreements in a problem-solving context (Fischer-Lokou et al., 2016). Besides the examples previously stated, there are many others which illustrate the advantages associated with the use of this practice, so that it seems interesting to investigate whether the contributions, directly linked with this technique, can also be extended to marketing. However, finding any information related with active listening applied to this specific study field proved to be a huge problem. Thus, the present paper intends to address this gap, by proving that the practice of active listening can indeed be present in the online field and that this same concept can act as a determinant of the online brand engagement.

In addition, a theoretical model capable of measuring the online engagement is also created (step 2 of Figure 2) based on the adaptation of seven concepts extracted from the literature, as can be seen in Table 1. 


\begin{tabular}{|c|c|c|}
\hline Concept & Definition & $\begin{array}{c}\text { Source } \\
\text { adapted from: }\end{array}$ \\
\hline Conversation & $\begin{array}{l}\text { Talk maintained between two or more parties } \\
\text { involved where ideas, feelings and thoughts are } \\
\text { presented, questions and answers are displayed and } \\
\text { information is exchanged. }\end{array}$ & $\begin{array}{l}\text { Cambridge } \\
\text { Dictionary, } \\
\text { 2017a }\end{array}$ \\
\hline Activation & $\begin{array}{l}\text { Consumer's level of energy, effort and time spent on } \\
\text { a brand along with the willingness to stay with that } \\
\text { same brand, instead of changing to another one. }\end{array}$ & $\begin{array}{c}\text { Hollebeek et } \\
\text { al., } 2014\end{array}$ \\
\hline Affection & $\begin{array}{l}\text { Consumer's degree of positive brand-related affect } \\
\text { can be described by: the level of positivity associated } \\
\text { with the consumer's emotional state (feeling quite } \\
\text { happy, proud, delighted and/or enthusiastic), which is } \\
\text { triggered by brand's actions or features - such as } \\
\text { product launches, promotions, among others. }\end{array}$ & $\begin{array}{c}\text { Hollebeek et } \\
\text { al., } 2014\end{array}$ \\
\hline $\begin{array}{l}\text { Negative } \\
\text { Affection }\end{array}$ & $\begin{array}{l}\text { Consumer's degree of negative brand-related affect } \\
\text { can be described by: the level of negativity associated } \\
\text { with the consumer's emotional state (feeling quite } \\
\text { sad, disappointed, angry or even feeling hateful), } \\
\text { which is triggered by brand's actions or features - } \\
\text { such as product launches, promotions, among others. }\end{array}$ & $\begin{array}{c}\text { Hollebeek et } \\
\text { al., } 2014\end{array}$ \\
\hline $\begin{array}{l}\text { Cognitive } \\
\text { Processing }\end{array}$ & $\begin{array}{l}\text { Consumer's level of brand-related thought processing } \\
\text { and elaboration embraces a wide range of actions } \\
\text { taken by consumers, such as: think about the brand, } \\
\text { use the brand, show interest in learning more about } \\
\text { the brand or be absorbed by it, in such a way that the } \\
\text { consumer forgets anything else. }\end{array}$ & $\begin{array}{l}\text { Hollebeek et } \\
\text { al., } 2014\end{array}$ \\
\hline Interaction & $\begin{array}{l}\text { The process in which consumers interchange ideas, } \\
\text { thoughts and feelings about the focus of engagement } \\
\text { (the brand), answering to other consumers' } \\
\text { comments, correcting them or even adding } \\
\text { information or facts to the discussion, with the } \\
\text { ultimate goal of protecting the brand. }\end{array}$ & Vivek, 2009 \\
\hline Love & $\begin{array}{l}\text { The concept goes beyond the ardent affection which } \\
\text { consumers can feel regarding a brand. This type of } \\
\text { love can be obtained through the combination } \\
\text { between emotion and passion and can be described } \\
\text { by the consumers' ability to feel a deep affection } \\
\text { towards one brand or its actions. }\end{array}$ & $\begin{array}{c}\text { Baldus et al., } \\
\text { 2015; } \\
\text { Cambridge } \\
\text { Dictionary, } \\
\text { 2017b }\end{array}$ \\
\hline $\begin{array}{l}\text { Online } \\
\text { Consumer } \\
\text { Brand } \\
\text { Engagement }\end{array}$ & $\begin{array}{l}\text { Psychological state that occurs by virtue of } \\
\text { interactive, co-creative experiences with a focal agent } \\
\text { or object that makes the consumer develop activities } \\
\text { such as liking and comment on one brand's Facebook } \\
\text { page. This (engagement) state is responsible for the } \\
\text { maintenance of the commitment and trust existent } \\
\text { between both parties involved, and consequently } \\
\text { leads to the perpetuation of the consumer' } \\
\text { engagement state towards that same brand. }\end{array}$ & $\begin{array}{l}\text { Brodie et al., } \\
\text { 2011; } \\
\text { Kabadayi and } \\
\text { Price, 2014; } \\
\text { Sashi, 2012 }\end{array}$ \\
\hline
\end{tabular}


Table 1: Concepts used to develop the engagement model.

\section{METHODOLOGY}

This research comprises two complementar studies as summarized in Figure 2.

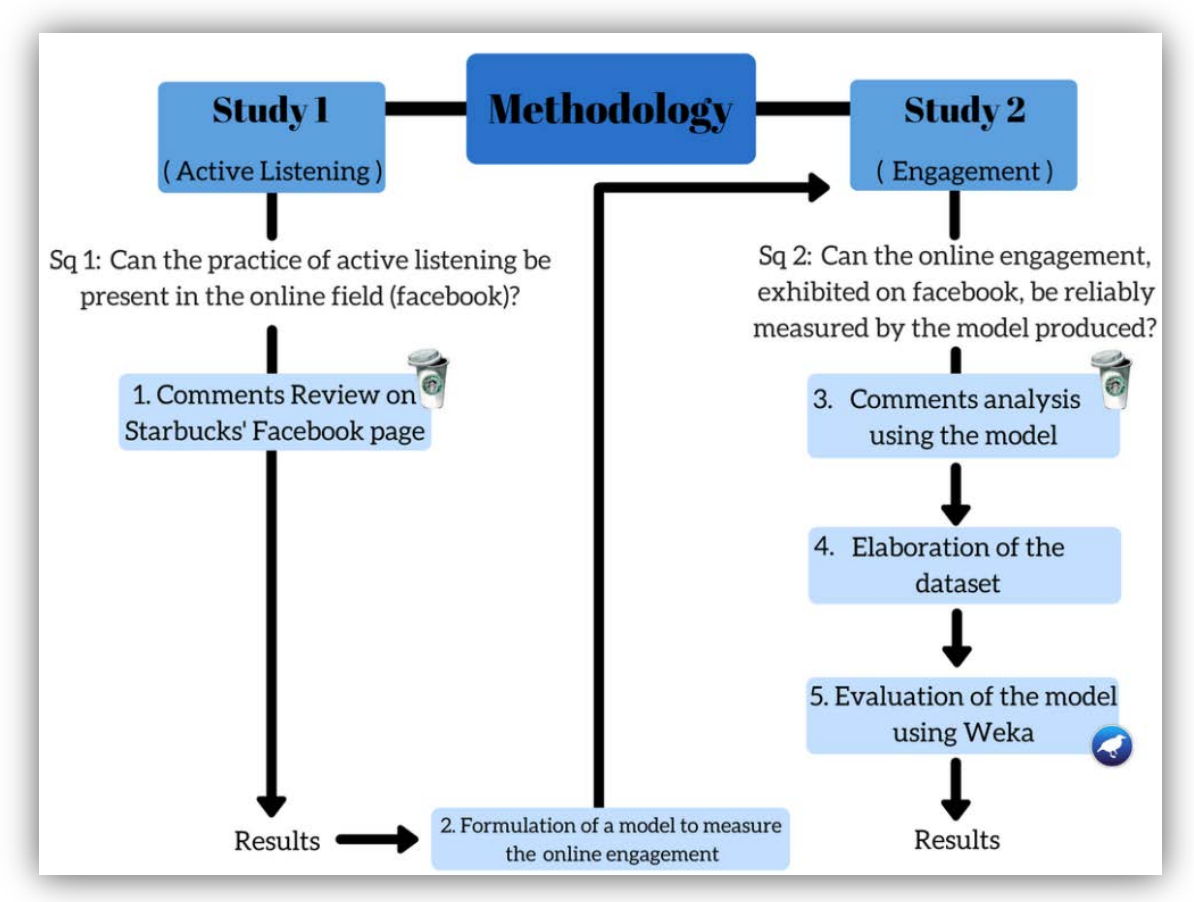

Diagram of the research design.
Figure

2:

The first study (Study 1) focuses on active listening and aims to discover wether this practice can, in fact, be present in the online field - more specifically on Facebook, since the definitions presented in the literature suggest that this practice requires interaction (Comstock, 2015) and consequently a face-to-face contact between the involved parties. As such, one comments review (step 1), capable of encompassing the emotions and engagement present in the interaction maintained between consumers and the chosen brand, is performed to associate the clues embedded in the comments with: specific language types, punctuation patterns and visual symbols (emotions and emojis). In order to discover what every single clue might be transmitting to the reader, this analysis use as methodological guides the articles written by Szurawitzki (2012) and Walther and D'Addario (2001) to ensure the reliability of the produced results. The use of these two articles is justified once the first provides ten useful indicators on how to analyse the language on Facebook and the second guides the analysis of other issues, such as message types (mixed or pure messages) and emotions' interpretation, completing the first paper and making the analysis more robust. Thus, the paper elaborated by Szurawitzki (2012) is used to elaborate the first step of the analysis: "1.1 Language" and is referred to as article a) throughout the analysis, whereas the second article is used to perform the second step of the analysis, designated as: "1.2 Message Type" and is referred to as article b).

Facebook was the chosen platform to carry out the comments review (Study 1), once it represents a solid social network which is used by many brands worldwide as a product 
disclosure tool, and as a mean of approaching and strengthening the existing relationship with consumers. In order to maintain Facebook dynamic, all comments were arranged by date (month-day-year) and time of posting, exhibiting a regular conversational structure between the two involved parties. Moreover, the priority is given to comments which present emotions and visual symbols, such as punctuation as well as answers by the brand (in this case, Starbucks). Furthermore, the brand-consumer conversation dynamic is maintained whenever possible, until the comments end or until they start interfering with other conversation considered more relevant to the review. Finally, in order to preserve the integrity and privacy of consumers, all names were replaced by fictitious ones to maintain ethics throughout the research (Malhotra, 2010), whereas the gender was kept intact to truly represent reality.

In addition to the comments review, a theoretical model capable of measuring the online engagement was also created (step 2) based on the adaptation of seven concepts extracted from the literature. Therefore, a significant number of comments were analysed on excel in accordance with the seven attributes previously defined and the information included in each comment was manually classified, by levels, in accordance with each attribute' scale (step 3). This process used Starbucks Facebook page once again, to maintain consistency with Study 1 and aimed at discovering the numerical level of engagement, included in each online comment.

Thereafter, the excel document was converted to CSV format and then to ARFF (Attribute-Relation File Format) (Waikato, 2002), in order to generate a dataset compatible with the data mining software Weka (step 4) which was created by the Department of Computer Science of the University of Waikato and is basically a collection of machine learning algorithms, created to perform data mining tasks in existing datasets or in new ones (Waikato, 2017), as is the case in this study.

Lastly, the software mentioned in the previous paragraph (Weka), was used to evaluate the accuracy of the model developed at the end of Study 1 (step 5). For that purpose, four distinct machine learning algorithms were chosen amongst the available ones: Zero R, Naïve Bayes, IBk and J48.

Study 2 evaluated the engagement model performed on Weka software (step 5). The second study used Weka software and the four available machine learning algorithms (= classifiers) mentioned above to evaluate the model levels of accuracy and noise, two critical features in determining its quality (Witten et al., 2011). Study 2 is organized into two distinct parts: I- Dataset Composition - where the total number of comments analysed as well as the numbers included in each attribute' levels are presented (conversation, activation, affection, negative affection, cognitive processing, consumer interaction, love, engagement) and part II- Applied Tests (classifiers) - where the results extracted in each test are exhibited, along with some relevant conclusions.

\section{MAIN FINDINGS}

Study 1 (comments review on Starbucks Facebook page) analysed three specific features of online comments: text, punctuation and visual clues (emotions and emojis) based on the ten indicators of the analysis model provided by Szurawitzki (2012), precisely developed to analyse the language in online contexts, namely on social networking sites. The model provided by Szurawitzki (2012) was only tested in a linear conversation, in which the author analyzed seven interactions between two individuals through his personal Facebook account. Study 1 went further since it applied the model in a different context, using a significant higher number of comments (60), which were elaborated by a broad number of distinct individuals, thus presenting more robustness in 
the findings. Additionally, Study 1 unveiled which were the visual symbols most often used by Starbucks' target on Facebook, within the two distinct types considered (emotions - facial expressions and emojis- others) revealing that: (1) smile was the most used emotion, always linked with positive feelings, in agreement to what was previously defended by Walter and D'Addario (2001), and showed the heart emoji is as commonly used as the smile, highlighting the importance that this type of visual cues emojis - already have on online communications. Therefore, Study 1 demonstrates that it is possible to capture emotions in online fields through the analysis and compilation of the meanings provided by text, punctuation and visual clues and due to that provides sufficient evidences to consider that AL practice is present on Facebook. As such, the conclusion drawn in Study 1 allows to answer to sub-question 1 ("Can the practice of AL be present in the online field - Facebook?") affirmatively, given the depth and robustness of the findings. Simultaneously, Study 1 presents a relevant discovery regarding $\mathrm{AL}$, since it shows this technique does not require face-to-face interaction to be successful or even to discover which emotions are conveyed by someone during his/her speech, in contrast to what was stated by several authors in previous literature (e.g., Rogers (1980), Barkai (1984), Levitt (2001), Robertson (2005), Comstock (2015), Heslip (2015) and Fischer-Lokou et al., (2016)) which addressed AL as being a purely physical practice. Lastly, Study 1 goes further than the study carried out by Bauer and Figl (2008), demonstrating that besides being important to initial interactions (in agreement with Bauer and Figl, 2008), AL is equally important to improve existing relationships as it helped strengthen the bond between Starbucks and its consumers, improving consumers mood and increasing their overall satisfaction with the brand.

Subsequently, Study 2 (the evaluation) supports the accuracy of the theoretical model of engagement that was developed with the aim of measuring the engagement "level" contained in 400 comments made by consumers and Starbucks on Facebook. It is possible to draw this conclusion since the engagement model was transformed into a database and further analysed by an independent data mining software (Weka), which revealed two important things regarding the model's quality: high accuracy and low noise. According to J58, one of the most powerful classifiers of the software chosen (Witten et al., 2011), the model achieved approximately $88.5 \%$ in the precision parameter. Together with this, the IBk test indicated the model is not noisy, once the accuracy level decreased as $\mathrm{k}$ increased, thus revealing a considerably good quality level. Hence, the set of tests performed on Weka software proved the engagement level registered on Facebook can be reliably measured by the model produced in Study 1, which consequently answers the sub-question 2 ("Can the engagement, exhibited on Facebook, be reliably measured by the model produced?") also in a positive manner.

Consequently, the set of aforementioned findings suggest that AL can actually bring concrete improvements to consumer-brand relationship (CBR), which allows to answer the core question of the study ("Can the practice of active listening improve the relationship between consumers and brands?") also positively, with rigor and robustness.

\section{CONCLUSIONS}

The theoretical engagement model developed in this paper has adjacent own specifications, which should be considered when companies/brands decide to apply it within their real context to improve the engagement results of their target market.

First, they must consider that the presented engagement model is so far purely theoretical and has not been yet applied into the daily context of a specific company yet. 
Consequently, the possibility of generating results with tough interpretations exists, together with the possibility of not being possible to apply the model successfully.

Second, brands and companies must take into account that the chosen brand to develop the model that although consistent and widely recognized worldwide is limited by the market sector where it is applied (food and beverage sector) and so are the obtained results. Hence, it is recommended that both entities start to apply the theoretical model in brands belonging to distinct market sectors to make possible comparisons between different sectors and allow the generalization of the findings presented here.

Third, brands and companies must also take into consideration the time limitations under which the study was performed and so they must extend the data collection process to all moments of the year, since it will provide them more robust and realistic data, thus avoiding potential misleading results that might occur due the lack of seasonal information.

\section{REFERENCES}

Baldus, B.; Voorhees, C.; \& Calantone, R. (2015). Online brand community engagement: Scale development and validation. Journal of Business Research, 68(5): 978-985.

Barkai, J. (1984). Active Listening: One Way to Be a Better Advocate, Counselor, and Businessperson, 20 TRIAL. Available https://www.researchgate.net/publication/228242852_Active_Listening.

Bauer, C.; \& Figl, C. (2008). Active listening in written online communication - A case study in a course on soft skills for computer scientists. Proceedings of the $38^{\text {th }}$ Frontiers in Education Conference: T1A1-T1A6. IEEE.

Brodie, R. J., Hollebeek, L. D., Juric, B., \& Ilic, A. 2011. Customer engagement: Conceptual domain, fundamental propositions, and implications for research. Journal of Service Research, 14(3), 252-271.

Cambridge Dictionary; Conversation; Available at: http://dictionary.cambridge.org/pt/dicionario/ingles/conversation; Accessed on $6^{\text {th }}$ of July of 2017a.

Cambridge Dictionary; Emotion; Available at: http://dictionary.cambridge.org/pt/dicionario/ingles/emotion; Accessed on $6^{\text {th }}$ of July of 2017b.

Comstock, N. W.; Active listening. In Comstock, Nancy W., Salem Press Encyclopedia, January, 2015; Available at: https://vpn2.iscte.pt/+CSCO+00756767633A2F2F7271662E6F2E726F6670627 56266672E70627A++/eds/detail/detail?sid=8f2bb961-6f26-4d95-aa5050924fa454a5\%40sessionmgr101\&vid=3\&hid=126\&bdata=JkF1dGhUeXBlPW lwLGNvb2tpZSxzaGliLHVpZCZsYW5nPXB0LWJyJnNpdGU9ZWRzLWxpd mUmc2NvcGU9c210ZQ\%3d\%3d\#AN=100259199\&db=ers\#AN=100259199\& $\mathrm{db}=e r s ;$ Published on January of 2015.

Dessart, L., Veloutsou, C., \& Morgan-Thomas, A. (2015). Consumer engagement in online brand communities: A social media perspective. Journal of Product \& Brand Management, 24(1), 28-42.

Fischer-Lokou, J., Lamy, L., Gueguen, N., \& Dubarry, A. (2016). Effects of active listening, reformulation, and imitation on mediator success: Preliminary results. Psychological Reports, 118(3), 994-1010.

Heslip, N. (2015). Active Listening: An important audit skill. New Perspectives on Healthcare Risk Management, Control \& Govern, 34(1), 14-24. 
Hollebeek, L., Glynn, M., \& Brodie, R. (2014). Consumer brand engagement in social media: Conceptualization, scale development and validation. Journal of Interactive Marketing, 28(2), 149-165.

Kabadayi, S., \& Price, K. (2014). Consumer - brand engagement on Facebook: Liking and commenting behaviors. Journal of Research in Interactive Marketing, 8(3), 203-223.

Levitt, D. (2001). Active listening and counselor self-efficacy: Emphasis on one microskill in beginning counselor training. The Clinical Supervisor, 20(2), 101-115.

Loureiro, C. (2012). Consumer-brand relationship: Foundation and state-of-art. Hershey, Pennsylvania: Hans Ruediger Kaufmann \& Mohammad Fateh Ali Khan Panni. Chapter 20, 413-434.

Maggiani, R. (2012). Social Media and Its Effect on Communication: Multidimensional interactions have altered the basic rules of communication; Available at: http://solaricommunication.com/toward-humanity/2015/02/04/social-media-andits-effect-on-communication/; Originally published on 2012.

Malhotra, K. (2010). Marketing Research: An Applied Orientation (6th ed.). Upper Saddle River, N.J.: London: Pearson Education.

Robertson, K. (2005). Active listening: More than just paying attention. Australian Family Physician, 34(12),1053 - 1055.

Rogers, R. (1980). A Way of Being. Boston: Houghton Mifflin.

Rogers, R.; \& Farson, E.; Active listening - Excerpt from Communicating in Business Today; Virtualmediationlab; Available at: http://www.virtualmediationlab.com/wpcontent/uploads/2012/08/active_listening.pdf; Published in 1987.

Sashi, C. (2012). Customer engagement, buyer - seller relationships, and social media. Management Decision, 50(2), 253-272.

Starbucks; Company information; Available at: https://www.starbucks.com/aboutus/company-information; Accessed on $6^{\text {th }}$ of August of 2017.

Szurawitzki, M. (2012). Analyzing the language of social networking sites - An analysis model. Proceedings of 24th Scandinavian Conference of Linguistics: 355-363. Available

at:

https://www.researchgate.net/publication/255723700_Analyzing the_Language of_Social_Networking_Sites_-

_An_Analysis_Model_Proceedings_of_the_24th_Scandinavian_Conference_of Linguistics.

Vivek, D. (2009). A Scale of Consumer Engagement. Ph.D., Department of Management and Marketing, University of Alabama, Tuscaloosa.

Waikato; Attribute-Relation File Format (ARFF); Available at: http://www.cs.waikato.ac.nz/ml/weka/arff.html; Posted on $1^{\text {st }}$ of April of 2002.

Waikato; Weka 3: Data Mining Software in Java; Available at: http://www.cs.waikato.ac.nz/ml/weka/; Accessed on $10^{\text {th }}$ of July of 2017.

Walter, J.; \& D'Addario, K. (2001). The impacts of emotions on message interpretation in computer-mediated communication. Social Science Computer Review, 19(3), 324-347.

Witten, I.; Frank, E.; \& Hall, M. (2011). Data mining: Practical machine learning tools and techniques (3rd ed.). Amsterdam: Morgan Kaufmann. 